\title{
Respiratory muscle strength in children with mild bronchial asthma disease
}

\author{
Kateřina Neumannová1,*, Zuzana Kováčiková1, Jakub Zatloukal², Milan Elfmark ${ }^{1}$, Jana Rydlová3, \\ and Miroslav Janura ${ }^{1}$
}

Faculty of Physical Culture, Palacký University Olomouc, Olomouc, Czech Republic; ${ }^{2}$ Department of Pulmonary Rehabilitation, University Hospitals of Leicester NHS Trust, Glenfield Hospital, Leicester, United Kingdom; and ${ }^{3}$ Miramonti Children's Medical Institution, Luhačovice Spa, Luhačovice, Czech Republic

Copyright: (C) 2017 K. Neumannová et al. This is an open access article licensed under the Creative Commons Attribution License (http://creativecommons.org/licenses/by/4.0/).

\begin{abstract}
Background: Respiratory muscle strength can be decreased in patients with asthma; however, it is not well-documented whether a mild bronchial asthma disease can affect respiratory muscle strength in children and can be associated with higher presence of breathing difficulties. Objective: The main aim of the present study was to compare respiratory muscle strength between children with asthma and age-matched healthy children. The next aim of this study was to assess the incidence of decreased respiratory muscle strength in children with asthma and healthy children and assess the effect of decreased respiratory muscle strength on the incidence of breathing difficulties. Methods: Children with mild bronchial asthma $(n=167)$ and age-matched, healthy children $(n=100)$ were recruited into this study. Pulmonary function tests, maximal inspiratory $\left(\mathrm{PI}_{\max }\right)$ and expiratory $\left(\mathrm{PE}_{\max }\right)$ mouth pressures and the incidence of breathing difficulty were evaluated in children with asthma and healthy controls. Results: The inspiratory muscle strength was similar between children with asthma and healthy children. Conversely, the expiratory muscle strength was lower in asthmatic children. There was a statistically significant difference between girls with asthma and healthy girls $\left(\mathrm{PE}_{\max }=81.7 \pm 29.8 \%\right.$ vs. $100.1 \pm 23.7 \%$ of predicted, $\left.p<.001\right) . \mathrm{PE}_{\max }$ was significantly higher in boys with asthma than in girls with asthma ( $\mathrm{PE}_{\max }=92.9 \pm 26.4 \%$ vs. $81.7 \pm 29.8 \%$ of predicted, $\left.p=.03\right)$. A higher incidence of breathing difficulties during physical activity (uphill walking, running, swimming) was confirmed in children with asthma with lower respiratory muscle strength. Conclusions: There was a higher prevalence of decreased expiratory muscle strength in children with asthma; therefore, respiratory muscle strength should be tested in these children, especially in those who are symptomatic.
\end{abstract}

Keywords: maximal inspiratory mouth pressure, maximal expiratory mouth pressure, ventilatory parameters, breathlessness, physical activities

\section{Introduction}

Bronchial asthma, defined as a heterogeneous disease that is usually characterised by chronic airway inflammation, is one of the most common chronic diseases in children (Global Initiative for Asthma, 2014). As a chronic disease, asthma can negatively influence a patient's quality of life, and it is necessary to start appropriately managing asthma as soon as possible to maintain or improve the quality of life. The main aim of comprehensive treatment in patients with asthma is to have asthma under control with as few symptoms

\footnotetext{
* Address for correspondence: Kateřina Neumannová, Department of Physiotherapy, Faculty of Physical Culture, Palacký University Olomouc, třída Míru 117, 77111 Olomouc, Czech Republic, e-mail: katerina.neumannova@upol.cz
}

as possible (British Thoracic Society Scottish Intercollegiate Guidelines Network, 2014; Global Initiative for Asthma, 2014). The comprehensive treatment consists of pharmacotherapy and non-pharmacological treatment. The goal of non-pharmacological treatment is to assist in improving symptom control as well as reduce future risk. Non-pharmacological treatment focuses on avoiding indoor and outdoor allergens and air pollutants; smoking cessation and avoidance of environmental tobacco smoke; education; exercise training - especially for patients with poor physical health; and on respiratory physiotherapy for patients with dysfunctional breathing patterns and ineffective expectorations. In some patients with asthma, nutritional and psychosocial support is also very important (Global Initiative for Asthma, 2014; Spruit et al., 2013). The 
standard assessment of a patient with asthma mainly focuses on asthma control (symptom control and the assessment of future risk of adverse outcomes), lung function tests and assessing comorbidities (British Thoracic Society Scottish Intercollegiate Guidelines Network, 2014; Global Initiative for Asthma, 2014). On the other hand, respiratory muscle testing as an important tool for early recognition of respiratory muscle weakness and cardiopulmonary exercise testing are not routinely used or recommended for evaluating a patient's functional status, although respiratory muscle weakness could be associated with a higher incidence of asthmatic symptoms, especially breathlessness, as well as other serious complications (Troosters, Gosselink, \& Decramer, 2005). Respiratory muscle testing is still not widely used in clinical practice for assessing respiratory muscle strength in children or adults with asthma, even though maximal inspiratory mouth pressure $\left(\mathrm{PI}_{\max }\right)$ is the only non-invasive test that can identify patients who have a risk of developing respiratory muscle fatigue during an acute asthmatic attack (Sette, Ganassini, Boner, \& Rossi, 1997). It has been documented that respiratory muscle weakness is associated with the long-term use of corticosteroids (Fauroux, 2003; McConnel, 2013; Perez, Becquart, Stach, Wallaert, \& Tonnel, 1996), and the reduction of the $\mathrm{PI}_{\max }$ is also associated with hyperinflation in adults with asthma (Weiner, Azgad, Ganam, \& Weiner, 1992). It is important to emphasise that insufficient respiratory muscle strength not only contributes to a higher risk of fatigue, it may also result in ineffective expectoration in patients with severe asthma disease, which can in turn lead to sputum retention and more, including a higher risk of atelectasis. Another frequent complication of respiratory muscle weakness is exercise intolerance from the presence of dyspnoea during various physical activities (Fauroux, 2003; Troosters et al., 2005).

Previous studies have reported a moderately impaired $\mathrm{PI}_{\text {max }}$ in young adults with asthma (McConnel, 2013; Weiner et al., 1992) and significantly reduced inspiratory endurance in adults with steroid-dependent asthma and non-steroid-dependent asthma compared with healthy controls (Perez et al., 1996). Recent research has noted that mild and moderate asthma in children and adolescents does not have a significant effect on respiratory muscle strength (de Oliveira, Lanza, \& Solé, 2012). Similarly, Marcelino, Da Cunha, Da Cunha, and Da Silva (2012) documented a lack of significant differences between the maximal inspiratory and expiratory $\left(\mathrm{PE}_{\max }\right)$ mouth pressures in children with and without asthma. They observed just slightly decreased values of $\mathrm{PI}_{\max }$ and $\mathrm{PE}_{\max }$ in children with asthma compared with children without asthma. These studies did not evaluate the percentage of predicted values, which could influence the results, because the values of the $\mathrm{PI}_{\max }$ and $\mathrm{PE}_{\text {max }}$ depend on age, weight and height in children (Heinzmann-Filho, Vidal, Jones, \& Donadio, 2012; Wilson, Cooke, Edwards, \& Spiro, 1984). Only few studies have investigated respiratory muscle strength according to the predicted values, for that reason the objective of the present study was to compare the values of the $\mathrm{PI}_{\max }$ and $\mathrm{PE}_{\max }$ as a percentage of the predicted values between children with asthma and age-matched healthy children. The next aim of this study was to assess the incidence of decreased respiratory muscle strength in children with asthma and healthy children and assess the effect of decreased respiratory muscle strength on the incidence of breathing difficulties.

\section{Material and methods}

\section{Subjects}

One hundred and sixty-seven children with mild bronchial asthma and one hundred healthy children voluntarily participated in this study. The children with mild bronchial asthma were clinically stable without any exacerbation of their disease and without any change in their medication within the prior two months. None of the children with asthma were being treated for any other disease. Bronchial asthma had been diagnosed at least one year prior to enrolment in the study according to the Global Initiative for Asthma Criteria (Global Initiative for Asthma, 2014). Mild asthma was well-controlled in all children with reliever medication alone or with low-intensity controller treatments, such as low-dose inhaled corticosteroids. The group of healthy children was matched for age and gender. Assessment of the healthy children was performed at primary and secondary schools in three different cities in the Czech Republic (Brno, Kroměříž, Olomouc). None of the healthy children were undergoing treatment for acute or chronic illness and they had no history of chronic respiratory disease. Assessment of children with asthma was performed at Luhačovice Spa during their baseline assessment. The study was approved by the Ethics Committee of the Faculty of Physical Culture, Palacky University Olomouc and was performed in accordance with the Ethical Standards on Human Experimentation, as outlined in the Declaration of Helsinki. The parents of all children gave written informed consent before the study was performed.

\section{Study design}

Children with asthma and healthy controls underwent lung function test and respiratory muscle strength assessment. All children performed respiratory muscle 
strength assessment for the first time, for that reason first three attempts were used for the learning process of the correct breathing manoeuvres. After relaxation pause the experimental assessment was performed.

\section{Lung function test}

Ventilatory parameters were performed with a Zan 100 Handy USB Spirometr (nSpire Health, Logmon, CO, USA) according to the guidelines of the American Thoracic Society (American Thoracic Society, 1991). The vital capacity (VC), forced expiratory volume in one second $\left(\mathrm{FEV}_{1}\right)$ and peak expiratory flow (PEF) were measured in children with asthma and healthy children. The values were expressed as a percentage of the predicted values.

\section{Maximal inspiratory and expiratory mouth pressures}

The respiratory muscle strength was measured using the Micro Respiratory Pressure Meter (Micro Direct, Lewiston, ME, USA). The measurements were performed with a mouthpiece and nose clip. Every child was individually instructed on how to perform the correct breathing manoeuvres for the $\mathrm{PI}_{\max }$ and $\mathrm{PE}_{\max }$ measurements. The measurements were performed in an upright sitting position with maximal respiratory effort and with a pause between each test. At least three acceptable measurements were taken and the measurement was finished when we gained the two largest values that had less than $10 \%$ of variation. The better value from these was used for further analysis. First, the $\mathrm{PI}_{\max }$ measurement was performed. $\mathrm{PI}_{\max }$ was measured as the maximal inspiratory effort after previous maximal exhalation (the $\mathrm{PI}_{\max }$ manoeuver begins from the residual volume). Second, the $\mathrm{PE}_{\text {max }}$ measurement was performed as a maximal expiratory effort after previous maximal inspiration (the $\mathrm{PE}_{\max }$ manoeuver begins from the total lung capacity). The $\mathrm{PI}_{\text {max }}$ and $\mathrm{PE}_{\max }$ values were expressed as a percentage of the predicted normal values for further analysis (Wilson et al., 1984). Values of $\mathrm{PI}_{\max }$ and $\mathrm{PE}_{\max }$ lower than $80 \%$ of predicted determined decreased respiratory muscle strength.

\section{Interview}

The interviews with the children with asthma focused on the presence of disease symptoms during the prior week. Participants were asked if they had suffered from wheezing, cough or breathing troubles. Questions about breathing difficulties were further specified by naming the activities during which they had had breathing problems (such as breathlessness or shortness of breath). Children were asked how much breathing difficulties bothered them during these activities during past week $(1$ - not bothered, 2 - bothered a bit, 3 - quite bothered, 4 - extremely bothered). The most frequent physical activities during which children described their breathing troubles were then further analysed. Healthy children were asked for the same questions.

\section{Statistical analysis}

Ventilatory parameters and respiratory muscle strength were compared between healthy children and children with asthma disease. Moreover, we also assessed the effect of decreased respiratory muscle strength on ventilatory parameters and the presence of breathing difficulties during physical actvities. Statistical analysis was performed using Statistica software (Version 10; StatSoft, Tulsa, OK, USA). Normality of data distribution was tested using the Kolmogorov-Smirnov test. Data were expressed as a mean $\pm \mathrm{SD}$. The dependent variables were normally disturbed; therefore an independent $t$-test was used for group comparison.

\section{Results}

\section{Baseline characteristics}

There were no significant differences in the age, vital capacity, and forced expiratory volume in one second or maximal inspiratory mouth pressure between children with asthma and healthy children (Table 1). Children with asthma had significantly lower PEF and $\mathrm{PE}_{\max }$. Healthy children had significantly higher heights and weights. For those reasons, statistical analysis of the $\mathrm{PI}_{\max }$ and $\mathrm{PE}_{\max }$ values was performed with the percentage of the predicted values of these parameters.

\section{Respiratory muscle strength in children with asthma and healthy children}

There were no statistically significant differences in the $\mathrm{PI}_{\text {max }}$ and $\mathrm{PE}_{\max }$ values between healthy boys and healthy girls. Similarly, there were no significant differences in the $\mathrm{PI}_{\max }$ values between boys and girls with asthma. Conversely, the $\mathrm{PE}_{\text {max }}$ values were significantly lower in girls with asthma than in boys with asthma $(p=.03$; Table 2).

Respiratory muscle strength was lower in children with asthma than in healthy children, but the only significantly reduced values were found for the $\mathrm{PE}_{\text {max }}$ in girls with compared to healthy girls $(p<.001$; Table 2$)$. Although there were no statistically significant differences in the $\mathrm{PI}_{\max }$ and $\mathrm{PE}_{\max }$ values between boys with and without asthma and in the $\mathrm{PI}_{\max }$ values between girls with and without asthma, there was a higher incidence of $\mathrm{PI}_{\max }$ and $\mathrm{PE}_{\max }$ values below $80 \%$ of the predicted values in children with asthma than in healthy children (Figure 1 and 2). 
Table 1

Baseline characteristics of the studied groups (mean $\pm S D$ or number)

\begin{tabular}{|c|c|c|c|}
\hline & $\begin{array}{l}\text { Children with asthma } \\
\qquad(n=167)\end{array}$ & $\begin{array}{l}\text { Healthy children } \\
\quad n=100)\end{array}$ & $p$ \\
\hline Sex & 83 girls; 84 boys & 50 girls; 50 boys & - \\
\hline Age (y) & $11.8 \pm 3.0$ & $11.9 \pm 2.0$ & .87 \\
\hline Height $(\mathrm{cm})$ & $149.5 \pm 17.2$ & $155.7 \pm 14.6$ & .01 \\
\hline Weight (kg) & $45.4 \pm 16.0$ & $49.8 \pm 16.6$ & .03 \\
\hline $\mathrm{VC}(\mathrm{L})$ & $2.99 \pm 1.04$ & $3.24 \pm 1.2$ & .43 \\
\hline VC (\% of predicted) & $92.1 \pm 15.2$ & $95.8 \pm 17.0$ & .38 \\
\hline $\mathrm{FEV}_{1}(\mathrm{~L})$ & $2.63 \pm 1.09$ & $2.77 \pm 1.01$ & .63 \\
\hline $\mathrm{FEV}_{1}(\%$ of predicted $)$ & $97.3 \pm 16.8$ & $98.0 \pm 12.3$ & .69 \\
\hline $\mathrm{PEF}(\mathrm{L} / \mathrm{s})$ & $5.29 \pm 1.69$ & $5.86 \pm 1.30$ & .02 \\
\hline PEF (\% of predicted) & $88.8 \pm 17.5$ & $94.5 \pm 12.1$ & .04 \\
\hline $\mathrm{PI}_{\max }\left(\mathrm{cmH}_{2} \mathrm{O}\right)$ & $66.2 \pm 26.2$ & $71.5 \pm 20.2$ & .08 \\
\hline $\mathrm{PI}_{\max }(\%$ of predicted $)$ & $91.4 \pm 33.1$ & $95.1 \pm 23.8$ & .32 \\
\hline $\mathrm{PE}_{\max }\left(\mathrm{cmH}_{2} \mathrm{O}\right)$ & $78.3 \pm 31.4$ & $88.2 \pm 23.5$ & .008 \\
\hline $\mathrm{PE}_{\max }(\%$ of predicted $)$ & $86.6 \pm 29.5$ & $97.6 \pm 22.9$ & .005 \\
\hline
\end{tabular}

Note. $\quad \mathrm{VC}=$ vital capacity; $\mathrm{FEV}_{1}=$ forced expiratory volume in one second; $\mathrm{PEF}=$ peak expiratory flow; $\mathrm{PI}_{\max }=$ maximal inspiratory mouth pressure; $\mathrm{PE}_{\max }=$ maximal expiratory mouth pressure.

Table 2

$P I_{\max }$ and $P E_{\max }$ values in percentage of predicted in children with asthma and healthy children (mean $\pm S D$ )

\begin{tabular}{lcccc}
\hline & $\begin{array}{c}\text { Girls with asthma } \\
(n=83)\end{array}$ & $\begin{array}{c}\text { Healthy girls } \\
(n=50)\end{array}$ & $\begin{array}{c}\text { Boys with asthma } \\
(n=84)\end{array}$ & $\begin{array}{c}\text { Healthy boys } \\
(n=50)\end{array}$ \\
\hline $\mathrm{PI}_{\max }$ & $87.9 \pm 35.5$ & $95.4 \pm 26.7$ & $94.8 \pm 27.2$ & $94.7 \pm 20.8$ \\
$\mathrm{PE}_{\max }$ & $81.7 \pm 29.8$ & $100.1 \pm 23.7^{\dagger}$ & $92.9 \pm 26.4^{*}$ & $95.2 \pm 22.1$ \\
\hline
\end{tabular}

Note. $\quad \mathrm{PI}_{\max }=$ maximal inspiratory mouth pressure; $\mathrm{PE}_{\max }=$ maximal expiratory mouth pressure; *statistical significance of the $\mathrm{PE}_{\max }^{\max }$ between girls with asthma and boys with asthma $(p=.03)$; ${ }^{\dagger}$ statistical significance of the $\mathrm{PE}_{\max }$ between girls with asthma and healthy girls $(p<.001)$.

\section{Ventilatory parameters in children with asthma and healthy children}

Children with asthma had significantly lower PEF than healthy children (Table 1). Moreover, PEF was significantly lower in children with asthma with decreased $\mathrm{PI}_{\max }$ and $\mathrm{PE}_{\max }$ values below $80 \%$ of predicted than in those with $\mathrm{PI}_{\max }$ and $\mathrm{PE}_{\text {max }}$ values greater than $80 \%$ of predicted. The vital capacity (VC) trended towards lower in children with asthma with decreased respiratory muscle strength (Table 3).

\section{Breathing difficulties}

Breathing difficulties were described in six healthy children (6\%) and in 126 children with asthma (75.4\%). None of the healthy children with normal respiratory muscle strength (values of $\mathrm{PI}_{\max }$ and $\mathrm{PE}_{\max }$ were higher than $80 \%$ of predicted) presented with breathing problems during the day or night. Only six healthy children with decreased respiratory muscle strength reported shortness of breath during running. By contrast, breathing problems were found in both asthmatic groups (Table 4). The incidence of breathing problems was higher in the asthmatic group who had lower values of $\mathrm{PI}_{\max }$ and $\mathrm{PE}_{\max }$. Children most commonly had asthma-related breathing difficulties during running, walking uphill, playing football and swimming. The activity that exacerbated the children's asthma and breathing difficulties the most was running. There was a significant relationship between respiratory muscle strength and breathing difficulties during running $(p<.001)$, walking uphill $(p<.001)$, playing football $(p<.001)$ and swimming $(p<.001)$. 


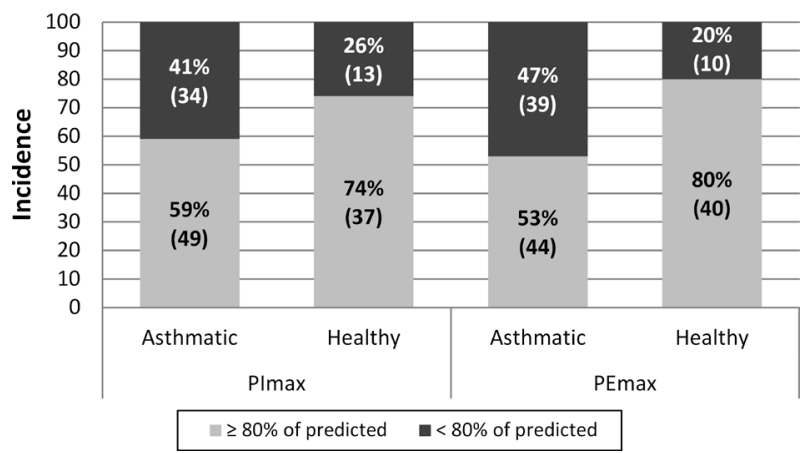

Figure 1. Distribution of maximal inspiratory $\left(\mathrm{PI}_{\max }\right)$ and maximal expiratory $\left(\mathrm{PE}_{\max }\right)$ mouth pressures in girls with asthma compared to healthy girls.

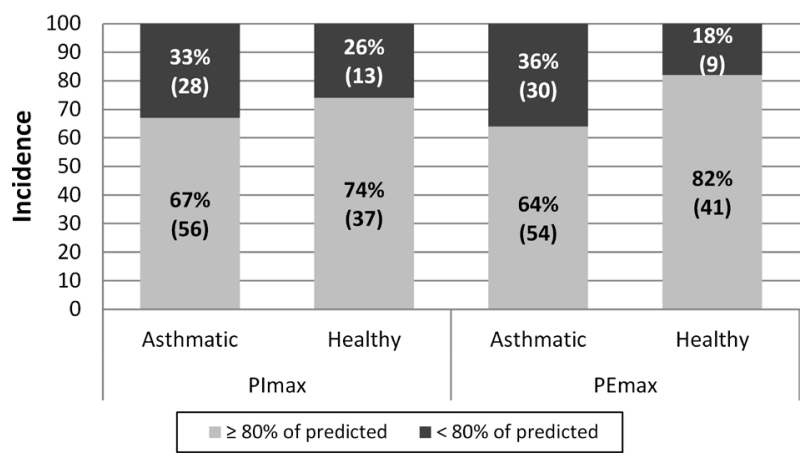

Figure 2. Distribution of maximal inspiratory $\left(\mathrm{PI}_{\max }\right)$ and maximal expiratory $\left(\mathrm{PE}_{\max }\right)$ mouth pressures in boys with asthma compared to healthy boys.

Table 3

Ventilatory parameters in percentage of predicted in children with asthma with normal and decreased respiratory muscle strength (mean $\pm S D$ )

\begin{tabular}{lccc}
\hline & $\begin{array}{c}\text { Maximal mouth pressures } \\
\geq 80 \% \text { of predicted }(n=98)\end{array}$ & $\begin{array}{c}\text { Maximal mouth pressures } \\
<80 \% \text { of predicted }(n=69)\end{array}$ & $p$ \\
\hline VC & $95.1 \pm 16.2$ & $89.1 \pm 14.6$ & .08 \\
FEV $_{1}$ & $98.7 \pm 28.2$ & $95.9 \pm 21.9$ & .38 \\
PEF & $96.2 \pm 17.1$ & $81.3 \pm 17.9$ & .001 \\
\hline
\end{tabular}

Note. $\quad \mathrm{VC}=$ vital capacity; $\mathrm{FEV}_{1}=$ forced expiratory volume in one second; $\mathrm{PEF}=$ peak expiratory flow.

Table 4

Incidence of breathing disorders in children with asthma with normal and decreased respiratory muscle strength

\begin{tabular}{lcc}
\hline & $\begin{array}{c}\text { Normal respiratory } \\
\text { muscle strength }(n=98)\end{array}$ & $\begin{array}{c}\text { Decreased respiratory } \\
\text { muscle strength }(n=69)\end{array}$ \\
\hline Running & $57(58.2 \%)$ & $69(100 \%)$ \\
Walking uphill & $10(10.2 \%)$ & $48(69.6 \%)$ \\
Football & $15(15.3 \%)$ & $21(30.4 \%)$ \\
Swimming & $5(5.1 \%)$ & $17(24.6 \%)$ \\
\hline
\end{tabular}

\section{Discussion}

The purpose of this study was to evaluate the respiratory muscle strength in children with mild bronchial asthma compared to healthy children. We confirmed a lower level of respiratory muscle strength in children with asthma than in healthy children, but a significant difference was reached only for the $\mathrm{PE}_{\max }$ in girls with asthma. Our results are in agreement with reports by Marcelino et al. (2012) and de Oliveira et al. (2012), who found that inspiratory muscle strength in children with mild bronchial asthma is similar to inspiratory muscle strength in healthy controls. Compared to these studies (de Oliveira et al., 2012; Marcelino et al., 2012), we evaluated the $\mathrm{PI}_{\max }$ and $\mathrm{PE}_{\max }$ values in the percentage of predicted values, providing us with more accurate results. It is reported (Heinzmann-Filho et al., 2012; Neder, Andreoni, Lerario, \& Nery, 1999; Wilson et al., 1984) that the $\mathrm{PI}_{\max }$ and $\mathrm{PE}_{\text {max }}$ values depend on age, weight and height. For that reason, our results of the decreased $\mathrm{PE}_{\max }$ values in girls with asthma differ from the results in the study by Marcelino et al. (2012). The authors of that study did not confirm any significant reduction in the $\mathrm{PE}_{\text {max }}$ values between healthy and children with asthma. The different results might be associated with evaluating the absolute $\mathrm{PI}_{\max }$ and $\mathrm{PE}_{\max }$ 
values (in $\mathrm{cmH}_{2} \mathrm{O}$ ) in their study. The assessment of the $\mathrm{PI}_{\max }$ and $\mathrm{PE}_{\text {max }}$ values as a percentage of predicted values should be better because children with and without asthma significantly differed in age, weight and height in their study.

Although there are similar values in children with and without asthma, except for the $\mathrm{PE}_{\max }$ values of the girls with asthma in our study, we found differences in the incidence of decreased respiratory muscle strength ( $\mathrm{PI}_{\max }$ and $\mathrm{PE}_{\max }$ values below $80 \%$ of predicted) between children with and without asthma. From our point of view, it is important to assess respiratory muscle strength according to the predicted values to evaluate respiratory muscle strength in children with asthma and gain more accurate results. The results from our study also highlighted a higher incidence of breathing problems during different physical activities in children with asthma with more deconditioned respiratory muscle strength. To the best of our knowledge, no previous studies have focused on respiratory muscle strength in association with the presence of breathing problems in children with asthma. Weiner, Magadle, Massarwa, Beckerman, and Berar-Yanay (2002) described similar results, reporting a higher presence of the perception of dyspnoea in women with asthma with more deconditioned respiratory muscle strength. They compared the $\mathrm{PI}_{\max }$ values between women and men with mild bronchial asthma and confirmed lower values of the $\mathrm{PI}_{\max }$ in women than in men, which was associated with a higher prevalence of breathing problems. We suggest that this topic should be studied further in the future to confirm the relationship between the respiratory muscle strength and severity of breathing problems in children and adults with asthma. Moreover, further research that focuses on the respiratory muscle strength in patients with asthma should examine the respiratory muscle strength in association with peripheral muscle strength and body composition. Children with asthma are more likely than healthy children to have significantly lower muscle mass and higher fat mass (Varekova \& Vareka, 2013). All of these parameters can be assessed non-invasively (Hronek et al., 2013; Varekova \& Vareka, 2013) and they might influence the respiratory muscle strength of patients with asthma. Even if previous research on respiratory muscle strength in children with asthma has not indicated that there are differences in the respiratory muscle strength between children with and without asthma (de Oliveira et al., 2012; Marcelino et al., 2012), our study findings indicate that respiratory muscle strength testing should be an important part of the complex assessment of children with asthma, especially in those who are symptomatic. Early recognition of decreased respiratory muscle strength should lead to including targeted chest physiotherapy focused on respiratory muscle training to comprehensive treatment of these patients. Sufficient respiratory muscle strength may help to maintain asthma disease under control.

\section{Study limitations}

There is a limitation of this study. We assessed children who only had mild bronchial asthma so the results might not be representative for children with moderate and severe asthma.

\section{Conclusion}

In conclusion, our results show that children who described a higher incidence of breathing difficulties during physical activity had more significantly decreased respiratory muscle strength. Therefore, respiratory muscle testing should be included in the complex assessment of children with mild bronchial asthma, especially in those who are symptomatic. Future studies of children with different severities of asthma disease are needed to evaluate the relationship between respiratory muscle strength and symptoms presence.

\section{Acknowledgments}

This work was supported by the project POST-UP, registration number: CZ.1.07/2.3.00/30.0004 and by the IGA grant No._FTK_2015_006. The authors would like to acknowledge Petr Štěpaník, Zuzana Jarošová, Helena Trnčíková and Andrea Strmisková who aided in this study.

\section{Conflict of interest}

There were no conflicts of interest.

\section{References}

American Thoracic Society. (1991). Lung function testing: Selection of reference values and interpretative strategies. American Review of Respiratory Disease, 144, 1202-1218.

British Thoracic Society Scottish Intercollegiate Guidelines Network. (2014). British guideline on the management of asthma. Thorax, 69(Suppl. 1), i1-i192.

de Oliveira, C. M. G., Lanza, F. C., \& Solé, D. (2012). Respiratory muscle strength in children and adolescents with asthma: Similar to that of healthy subjects? Jornal Brasileiro de Pneumologia, 38, 308-314. 
Fauroux, B. (2003). Respiratory muscle testing in children. Paediatric Respiratory Reviews, 4, 243-249.

Global Initiative for Asthma. (2014). Global strategy for asthma management and prevention 2014. Retrieved from http://www.ginasthma.org

Heinzmann-Filho, J. P., Vidal, P. C. V., Jones, M. H., \& Donadio, M. V. F. (2012). Normal values for respiratory muscle strength in healthy preschoolers and school children. Respiratory Medicine, 106, 1639-1646.

Hronek, M., Kovarik, M., Aimova, P., Koblizek, V., Pavlikova, L., Salajka, F., \& Zadak, Z. (2013). Skinfold anthropometry-the accurate method for fat free mass measurement in COPD. COPD: Journal of Chronic Obstructive Pulmonary Disease, 10, 597-603.

Marcelino, A. M. F. C., Da Cunha, D. A., Da Cunha, R. A., \& Da Silva, H. J. (2012). Respiratory muscle strength in asthmatic children. International Archives of Otorhinolaryngology, 16, 492-496.

McConnel, A. (2013). Respiratory muscle training: Theory and practice. Edinburgh, United Kingdom: Churchill Livingstone.

Neder, J. A., Andreoni, S., Lerario, M. C., \& Nery, L. E. (1999). Reference values for lung function tests. II. Maximal respiratory pressures and voluntary ventilation. Brazilian Journal of Medical and Biological Research, 32, 719-727.

Perez, T., Becquart, L. A., Stach, B., Wallaert, B., \& Tonnel, A. B. (1996). Inspiratory muscle strength and endurance in steroid-dependent asthma. American Journal of Respiratory and Critical Care Medicine, 153, 610-615.
Sette, L., Ganassini, A., Boner, A. L., \& Rossi, A. (1997). Maximal inspiratory pressure and inspiratory muscle endurance time in asthmatic children: Reproducibility and relationship with pulmonary function tests. Pediatric Pulmonology, 24, 385-390.

Spruit, M. A., Singh, S. J., Garvey, C., Zu Wallack, R., Nici, L., Rochester, C., ... Wouters, E. F. M. (2013). An official American Thoracic Society/European Respiratory Society statement: Key concepts and advances in pulmonary rehabilitation. American Journal of Respiratory and Critical Care Medicine, 188, e13-e64.

Troosters, T., Gosselink, R., \& Decramer, M. (2005). Respiratory muscle assessment. In R. Gosselink \& H. Stam (Eds.), European respiratory monograph 31: Lung function testing (Vol. 10, pp. 57-71). Wakefield, United Kingdom: European Respiratory Society Journals.

Varekova, R., \& Vareka, I. (2013). How to estimate overweight in pubescent asthmatics? Advances in Medical Sciences, 58, 331-337.

Weiner, P., Azgad, Y., Ganam, R., \& Weiner, M. (1992). Inspiratory muscle training in patients with bronchial asthma. Chest, 102, 1357-1361.

Weiner, P., Magadle, R., Massarwa, F., Beckerman, M., \& Berar-Yanay, N. (2002). Influence of gender and inspiratory muscle training on the perception of dyspnea in patients with asthma. Chest, 122, 197-201.

Wilson, S. H., Cooke, N. T., Edwards, R. H. T., \& Spiro, S. G. (1984). Predicted normal values for maximal respiratory pressures in caucasian adults and children. Thorax, 39, 535-538. 